\title{
A review of effective flood forecasting, warning and response system for application in South Africa
}

\author{
LA du Plessis \\ Department of Agricultural Economics, University of the Free State, Bloemfontein, South Africa
}

\begin{abstract}
Cyclone Eline caused severe flood damage in South Africa during February 2000. It has been estimated that the total amount lost was approximately R3 000 million. South African farmers lost more than 50\% of their export products. Flood damages and disruptions to humans and animal species were even bigger in Mozambique.

The emphasis in South Africa is still on, inter alia, structural mitigation measures. Policy-makers seek foreign support and finances, especially during the reconstruction phase after floods, for reparation purposes only. Little to no attention has been given to scientific hazard and risk assessments to determine a sustainable flood standard for different river reaches, which will contribute to appropriate mitigation and prevention strategies. The aim, after flood disasters, is primarily to ensure that flood losses will be covered and to restore the level of existence of flood victims to where it was before the flood. Furthermore, mainly because of institutional problems currently experienced in South Africa, roles and responsibilities of institutions involved in disaster management are not clearly identified. Last mentioned are the reason for absence in South Africa of a formal flood forecast, warning and response system (FFWRS). In most cases where a flood warning system exists, there is evidence that it is insufficient, mainly because of a lack of knowledge and understanding of a well-functioning, appropriate FFWRS.

Sustainable prevention and mitigation strategies should be achieved within a holistic integrated catchment management approach. Such approach is multidisciplinary and is therefore not based on a single engineering solution. The main aim of this paper is to discuss one aspect covered by a holistic integrated catchment management approach, namely a flood forecast, warning and response system, which contributes to the prevention and mitigation of flood losses.
\end{abstract}

\section{Introduction}

During February 2000 South Africa and Southern Africa experienced severe floods, which caused extreme flood damage to roads, infrastructure, agricultural crops and property. It has been estimated that the total impact of the February 2000 floods for South Africa alone was more then R3 000 million. South African farmers in the disaster-stricken areas lost more then $50 \%$ of their export products. The question arises, especially from policy-makers and communities; what can be done to at least reduce the negative impacts of floods?

The answer to this question would be to implement effective and efficient flood-plain management in order to ensure sustainable development. A flood-plain management plan must be comprehensive and must provide an effective framework for the development of land and water resources in catchment areas (Dempster \& Brammer, 1995). The primary objective of a flood management plan is to attempt to find permanent solutions to flood problems. In the past 10 years in various places in the world, it has been shown in several studies that the flood management policies of specific countries have influenced the course of development in flood plains without managing to halt it (Dempster \& Brammer, 1995; Parker 1995; Galloway 1995; New South Wales Government, 1986). In order to comply with the idea of sustainable, integrated long-term planning in the compilation of development plans (Adams, 1995; Ghosh, 1991), a holistic approach to integrated catchment management is proposed for South Africa. "A holistic co-operative approach is necessary which would ensure in achieving a sustained

푱(051) 401-2721; fax: (051) 401-3473; e-mail: duPlesLA@ sci.uovs.ac.za Received 27 July 2000; accepted in revised form 28 November 2001. minimal standard human life for the people and protection of the environment. There is no other alternative for the survival and betterment of the people of the region" (Bancid, 1995).

An effective mitigation and prevention strategy will inter alia be to develop and implement a flood forecast, warning and response system (FFWRS). Bancid (1995) indicated that FFWRS is recognised as a highly cost-effective, flood mitigation measure.

The main aim of this paper therefore is firstly to review holistic approaches to integrated catchment management, whereafter a flood forecast, warning and response system will be discussed in detail as a cost-effective flood prevention and mitigation strategy for catchments.

\section{Integrated catchment management}

Various activities are associated with sustainable integrated catchment planning, as depicted graphically in Fig. 1.

Activities listed in Fig. 1 should firstly be investigated individually by provincial and local authorities, whereafter results should be integrated in order to arrive at a sustainable integrated catchment management plan. A multidisciplinary approach is clearly indicated. In terms of this approach it would be unreasonable to expect provincial and local governments to house expertise and specialist services on a permanent basis. Consequently, an institutional network approach is proposed for South Africa whereby specialised services, most of which could and should be privatised, could be provided to provincial and local authorities. This 'approach will facilitate installation of the desired institutions for South Africa and reduce hazard losses in flood plains (Haque \& Zaman, 1993).

A second question can be posed: What exactly do all activities in Fig. 1 entail? Because of the extent of activities in Fig. 1 it will 


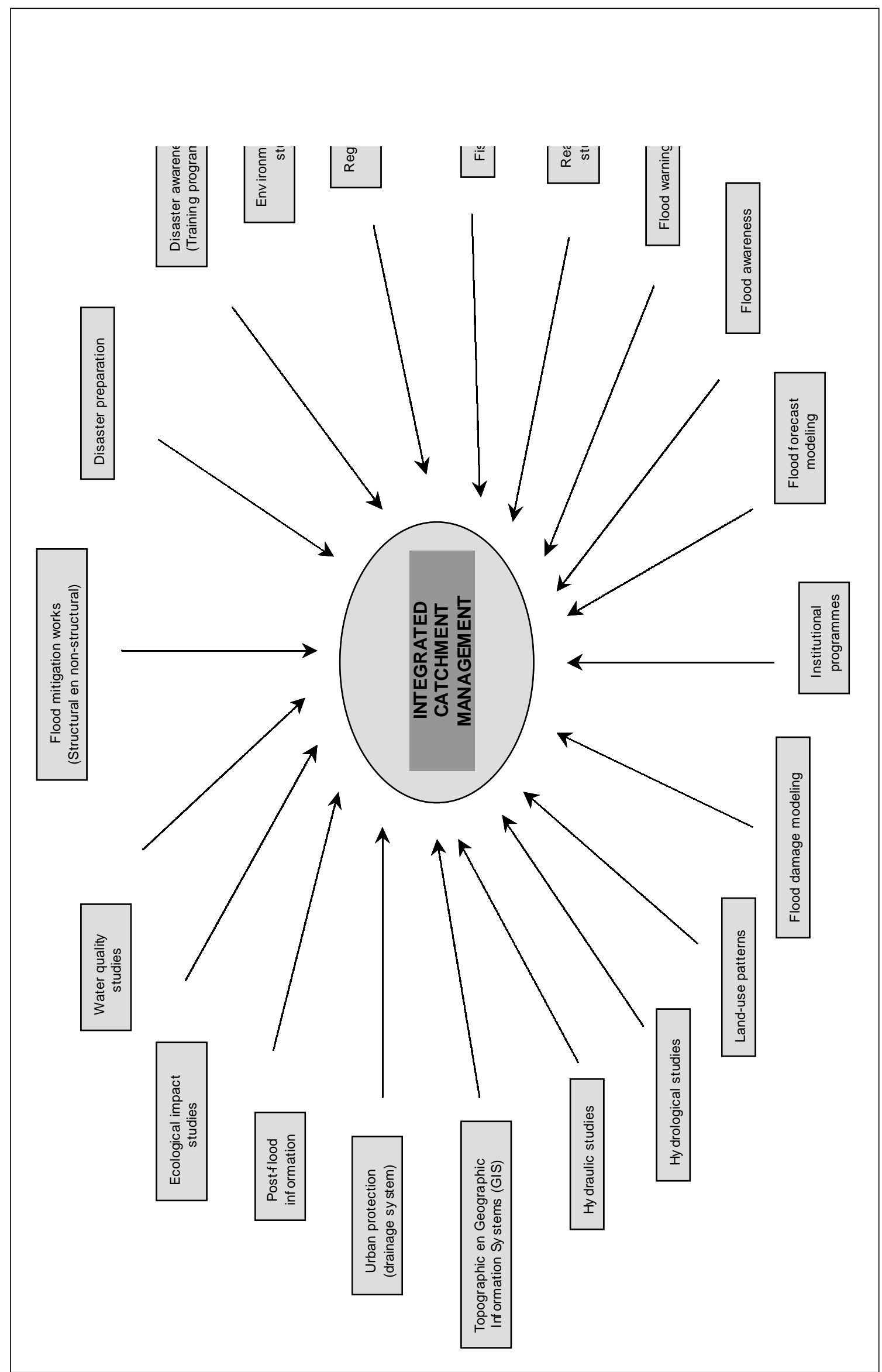

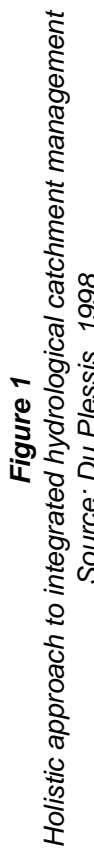




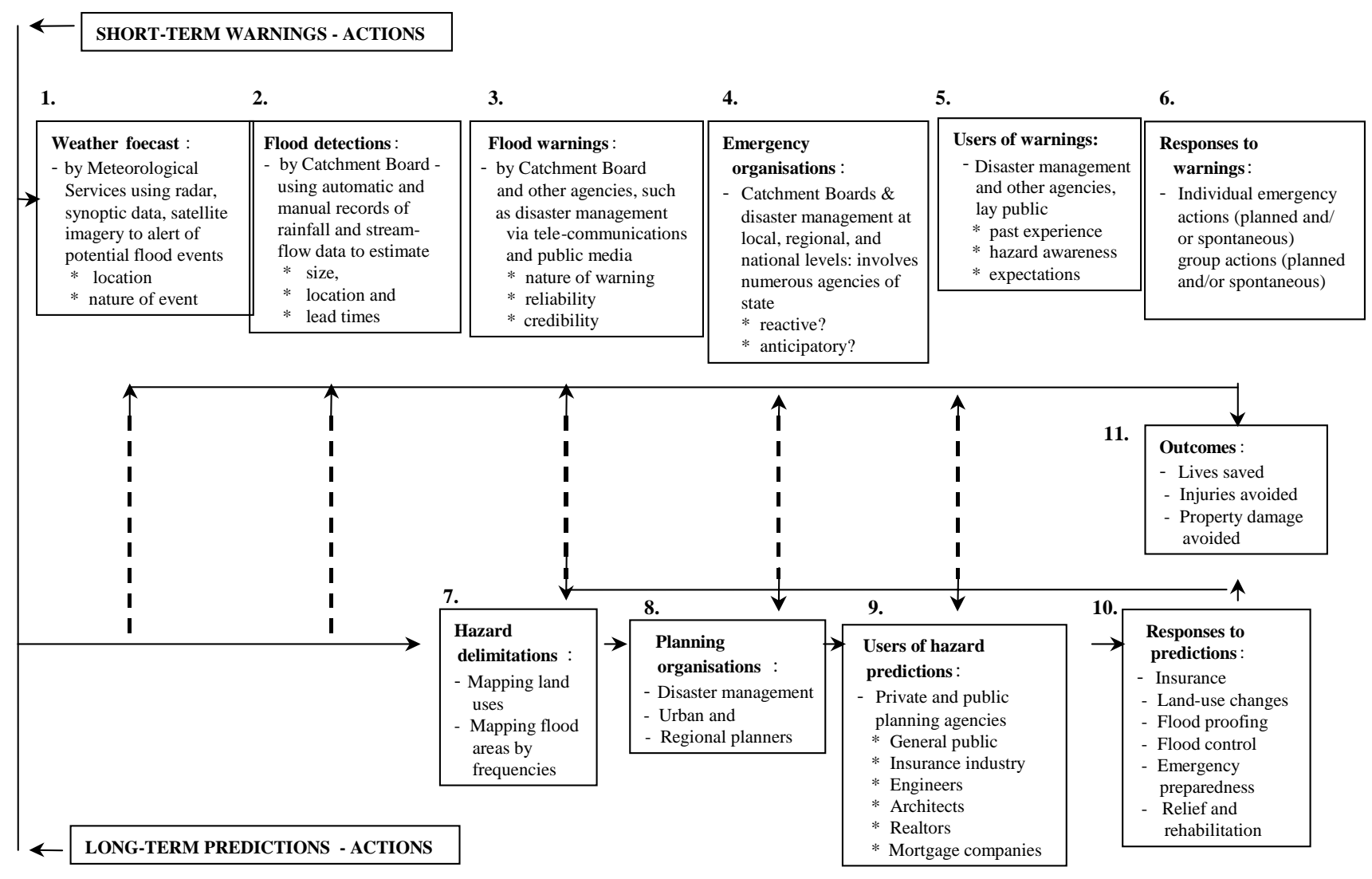

Figure 2

Key elements of a flood warning system Source: Downing (1977)

not be possible to discuss each in detail. The main aim of this paper is to review on an FFWRS as part of a flood mitigation and prevention strategy in catchment management.

\section{Flood forecasting, warning and response systems (FFWRS)}

The main purpose of an FFWRS is to avert or minimise loss of life. France expanded this vision and defined the purpose of the FFWRS as a means of establishing public safety, to reduce damage to property and to relieve public anxiety (Parker and Fordham, 1996). A warning and evacuation system should be developed for South Africa in order to lower the risk of human loss of life cost effectively (Alexander, 1993). Bancid(1995) expressed the opinion that: "Flood forecasting and warning has been identified as a key component that could exert major benefits on numerous aspects of national life, with considerable potential for improving the national economy. As such it is recognised as a highly cost effective, nonstructural measure". In Europe an FFWRS is implemented to reduce material, human and cultural losses (Parker and Fordham, 1996). Put differently, FFWRS is one component of various flood control options that could be installed to reduce tangible flood losses (Smith and Handmer, 1986; Krzysztofowicz and Davis, 1983).

Although flood forecasting, warning and awareness programmes are depicted separately in Fig. 1, they cannot be regarded as such, but should rather be treated in harmony with one another. The literature refers to these aspects as being a unit and names them "flood forecasting, warning and response systems" (FFWRS). As soon as one of these components fails, the whole system will be rendered ineffective (Parker and Fordham, 1996). Recent floods in France (1987, 1988 and 1992) claimed 83 lives and led to billions of francs in flood damage, since they could not be forecast and because no FFWRS had been available (Parker and Fordham, 1996). Sixty per cent of the Netherlands lies below mean sea level and hence flood protection and FFWRS are strategically very important. Downing (1977) discussed key elements involved in a flood warning system which could be represented diagrammatically (Fig. 2).

The key elements in Fig. 2 are short-term warning actions, starting with weather forecasting procedures, continuing to disseminating flood warnings by Catchment Boards, and ending with the response to the flood warning. Secondly it entails longterm prediction actions, which consist of hazard delimitation by using mapping procedures to avoid loss of lives and damage to property

\section{Integrated flood warning system}

Smith and Handmer (1986) stressed four important properties of an FFWRS, namely:

- An FFWRS is distinguished as a cost-effective option for flood reduction.

- FFWRS remains applicable to situations where other flood control strategies are no longer relevant or feasible.

- At the recognition of new risks that have to be reduced, greater emphasis is placed on FFWRS. 
- With the development of new forecasting techniques greater emphasis can be placed on FFWRS.

Alexander (1993) distinguishes between a passive and an active flood warning system. Passive warning entails making inhabitants aware of flood hazards by inter alia the marking of flood lines, beacons and telephone standards. In this way responsibility can be transferred to communities for observing floodwaters and taking the necessary actions. The greatest disadvantage of a passive warning system is that inhabitants start to lose interest and the required results are therefore not achieved. Active warning is more formal and should comply with three conditions, namely: immediate action when warning is issued; it must be physically possible to inform all people timely about flood hazards; and an appropriate public control centre so that information can be received, processed and interpreted in order that appropriate action can be taken. Situations do exist inside and outside the jurisdiction of local authorities where active flood warning is unpractical. The only feasible solution, especially for smaller communities, is to provide facilities which enable communities to handle their own river watch system (Alexander, 1993).

\section{Flood warning stages}

An integrated flood warning system can be divided into four stages, namely:

- preparation;

- warning decisions;

- warning distribution/broadcasting; and

- the receipt and response stage (Smith and Handmer, 1986).

In contrast to Smith and Handmer (1986), Krzysztofowicz and Davis (1983) merely distinguish between forecast and response stages. Rainfall data processing is divided into three separate phases by some authors, namely the registration of field data, data collection and hydraulic processing (water depth and velocity), while response is again divided into the decision-making process, the decision that is taken and the implementation stage (Krzysztofowicz and Davis, 1983; Bancid, 1995). The decision to warn is critical to an FFWRS. Consequently, a standardised warning system is required within a catchment. A network of data collection systems should exist which is forwarded to a riverforecasting centre, after which it is transformed to a hydraulic forecasting procedure.

Sound communication among weather forecast, flood forecast, flood defence, disaster management and media agents is required for effective FFWRS (Parker and Fordham, 1996). For forecasting purposes, data communication and a data distribution system are indispensable components in the transformation process of hydraulic data such as water levels, rainfall, flow velocities and runoff. Methods such as real-time data distribution by means of wireless stations are commonly used in Bangladesh (Bancid, 1995). The forecasting procedure includes all hydrological (flood frequency and cumecs) and hydraulic models (rainfall-runoff models). The extent of a flood as well as a specific time of occurrence is included in a forecast. A manner of communication must be established (radio, TV and telephone) to identify an appropriate broadcasting/ distribution channel. Private and other organisations can then transmit the information in the form of a flood warning to potentially endangered inhabitants after having received a flood forecast from the river centre. The decision-making actions include all formal decision- making such as the degree and extent of response, type of protection and allocation of resources to various protection activities.

\section{False warning}

Considerably more attention should be given to the avoidance of false warnings, since false warnings can lead to a lowering in response of flood-plain dwellers. An integrated flood warning system focuses on three important factors, namely relevant institutions, technology used in flood forecasting and issuing and the level of education of inhabitants receiving warning as well as their reaction to it (Smith and Handmer, 1986). Smith and Handmer (1986) depicted a conceptual integrated flood warning system diagrammatically and can be consulted for more comprehensive information.

Where a short warning time and inaccurate forecasts are evident, flood warnings are found to be ineffective in practice. Therefore flood warning systems are worthless if the warning does not reach the inhabitants timely and will also be of no value if inhabitants do not understand the warning in order to be able to respond to it (Krzysztofowicz and Davis, 1983). In this connection Parker and Neal (1990) declared that flood-plain dwellers would prefer a warning during daytime as opposed to night-time. The handling and evacuation of equipment and livestock are clearly implemented more easily during the day.

The methodology should take into consideration all stages of the flow of information, from the establishment of data, preparation of forecasts, issuing of warnings by the media and the decisionmaking and implementation of various actions by inhabitants. Planning and investment decisions concerning the development or improvement of a specific FFWRS should be based on a systems analysis at local level. Such an approach is indispensable since differences occur between individual systems. Variations occur due to multiplicity and complexity of factors such as hydrology, organisation, behaviour and the economy, all of which affect the FFWRS (Krzysztofowicz and Davis, 1983).

\section{Institutional arrangement}

Uncertainties regarding the roles of various governmental institutions have led to serious financing and implementation problems in respect of an FFWRS at all government levels. In Australia a central body, the State Emergency Services was founded to distribute information (Smith and Handmer, 1986). In addition a centralised Commonwealth based system is employed in Australia which centres on the Meteorological Bureau. This Bureau provides information to forecasting centres in regions. In England flood warning systems are handled on a regional basis within the system of the water authorities. In 1972 the Flood Forecasting and Warning Centre in Bangladesh came into existence as a permanent entity. Tasks such as data communication and distribution, updating of flood forecasting, formulation of forecasting and distribution of forecasting messages are performed by the Flood Forecasting and Warning Centre. This centre functions in close co-operation with the Meteorological Department. Appropriate liaison exists between the centre and the Meteorological Department so that data distribution is not limited (Bancid,1995). Close liaison is also maintained with the Space Research and Remote Sensing Organisation in order to receive satellite images for flood forecasting purposes. Satellite images that show the morphological changes in a river system and in the flooded areas are requested from time to time. Co-operation is in place with the Disaster Management Bureau in order to determine the impact of flood disasters. Communication is set up with flood-related project personnel for the guidance of flood-plain inhabitants towards the desired response during natural disasters (Bancid, 1995). 
In the Netherlands a disaster management organisation has been integrated with a national co-ordinating centre. A Disaster Act formulated in 1985 defines the role and responsibilities of public authorities during disaster management (Parker and Fordham, 1996). Case studies carried out by Parker and Fordham (1996), show that the Netherlands have acquired the philosophy of learning from past experiences. The result of this is that potential flood damage decreases with time. During floods, the FFWRS is managed from three control rooms, namely the Department of Water Affairs, the Mayors office and the Police Communications Centre. Incoming information is automatically relayed to all threecontrol rooms so that communication multiplies threefold in effect (Parker and Fordham, 1996). The daily activities of the centre are summarised by Bancid 1995) and can be consulted for more particulars. In contrast to this the national river authorities in the United Kingdom are primarily responsible for flood protection and FFWRS initiatives.

The efficiency of an integrated FFWRS is best promoted by institutions that emphasise local decision making, rather than focusing on centralised structures. According to Smith and Handmer (1986) a degradation of systems occurs when decision-making is removed from the realm of local experience of a river system. Centralised structures not only lead to complex broadcasting methods, but also to intensive co-ordinating systems which are hampered by poor communications and inexperienced personnel (Smith and Handmer, 1986). In England many water authorities implement a flood forecasting and warning system that is based on a rainfall runoff model. Experiments have already been conducted in an attempt to prolong the warning time by making use of radar data. In this way information on the duration and intensity of rainfall can be used for simulation, in preference to river flow data. During the 1982 flood in York, England, the flood warning system functioned very well, distinctly as a result of the fact that the public had sound flood experience, and therefore knew how to respond to flood warnings (Parker and Neal, 1990).

National governments ought to be primarily responsible for the monitoring of rainfall in the form of the collection and storing of data, the purchasing, installation, and maintenance of equipment, and furthermore for distributing these data to provincial and local authorities. Regional authorities should be more concerned with the gathering and storing of river level data. In other cases however, warning systems may be locally to totally privately orientated. With modern communication technology in particular, the necessity of central expertise is becoming less pronounced, with a greater need for local warning systems. Be this as it may, priorities must be clearly spelt out for an FFWRS at all government levels.

\section{Cost-effectiveness}

The potential damage which can be obviated from a national point of view by responding to a flood warning, is much greater then the cost of installing an FFWRS (Krzysztofowicz and Davis, 1983). Usually the cost associated with flood warning is lower than other flood control measures, with the result that more communities could benefit from it (Smith and Handmer, 1986).

The maintenance of an existing FFWRS and the development of future systems require funding. Expenses such as general overheads associated with the functioning of a flood forecasting and warning centre (buildings, office space, furniture and so forth), remuneration of personnel staffing and operating the centres, capital investment on equipment for the measurement of river levels and precipitation, communication systems, hydrological models, and communication reports for the issuing of warnings to the media and public as well as maintenance costs, must be incurred.

The upkeep and operation of an FFWRS can be done more costeffectively when, for instance, the maintenance and functioning of both river level and rainfall stations are run by one organisation. A flood forecasting and warning centre should provide back-up assistance such as advice, streamflow simulation, software, meteorological and hydrological forecasts, training in equipment and monitoring of floods to provincial and local authorities. Local authorities, on the other hand, should purchase equipment for testing stations, install and maintain it and be responsible for development and implementation of a flood response plan.

\section{Evaluation of FFWRS}

Finally, an FFWRS has to be evaluated after the flood incident has passed. If systems are evaluated on a regular basis the necessary adjustments can be made, with resulting improvement of their effectiveness. For evaluation purposes, a distinction can be made between the forecasting and warning system, and the response system. A flood forecasting and warning system can be regarded as an information system. The appropriateness of the system can be evaluated by determining the potential and actual quality of the information provided. The response system, on the other hand, can be regarded as a decision-making system and can be evaluated on the basis of an optimal and actual response strategy (Smith and Handmer, 1986).

Evaluation of warning systems is aimed at bringing about improvement of existing systems. Methodological and conceptual problems, such as the definition of warning, warning accuracy and problems of conceptualising floods as disasters, give rise to the problem that research findings from different researchers cannot be easily compared. Practical and technical problems cause invalid results. Jointly, these problems harm the institution of appropriate policy with non-structural measures. Improvements in an FFWRS can indeed be economically advantageous, but can also lead to negligible additional consumer satisfaction (Smith and Handmer, 1986).

Several steps should be present in the evaluation process. Firstly, appropriate performance standards (quantitative and qualitative) should be established. More specifically, quantitative standards refer to input, output and effectiveness standards. Input standards will typically deal with inputs required for an appropriate FFWRS, while output standards concentrate on forecasting, warning and response.

Efficiency standards can then be formulated by expressing certain inputs and outputs that have a narrow and meaningful relationship by means of a ratio. In this, corrective actions must be taken in order to improve the performance of a warning system.

\section{Evaluation approaches}

\section{- Size of area}

Parker and Neal (1990) distinguished four approaches towards evaluation of an FFWRS. The first approach investigates the size of the area to be served with flood warnings (extent of coverage). Although this approach does have strategic planning value in particular, it does not measure the quality of a warning system and therefore does not take into account any failures or shortcomings within a warning system. It is therefore indeed possible when employing only the approach mentioned, to have a situation where the quality of the warning system decreases while the area covered is expanded. 


\section{- $\quad$ Flood losses}

A second approach is to determine the losses that can be prevented by a flood warning system. The larger the benefit that can be achieved, the better a flood warning system can function. The greatest problem with this method is that it is necessary not only to determine the tangible direct flood damage, but also to identify the indirect, non-tangible losses. By not quantifying the latter impacts, a distorted picture could be obtained of the behaviour of a flood warning system. The advantages of an improved FFWRS are the differences in the impact of floods that occur with a longer warning time or the greater accuracy with which floods are forecast, rather than the difference between maximum potential damage and the total true flood damage (Smith and Handmer, 1996).

\section{- Community satisfaction}

The satisfaction of communities with regard to warning services can also be used to evaluate a flood warning system. Several problems arise with this approach. Flood-plain inhabitants experience one or two floods in a lifetime and hence the satisfaction of inhabitants will only be measured in the course of one or two flood incidents. Consequently, public satisfaction with flood warning during smaller floods will not necessarily serve as a sounding board for public contentment during bigger floods. Where dwellers are poorly informed regarding the risk of floods, the possibility exists that high public satisfaction with a warning service may give rise to an underestimation of the danger of flooding and an overestimation of the effectiveness of a warning system.

\section{- Performance evaluation}

Finally, the shortcomings of a warning system can be evaluated by identifying, categorising and documenting the shortcomings of flood warnings. The advantage of this method is, inter alia, that a specific division of a system could easily be improved, while on the other hand the greatest problem posed to the approach is the gathering of suitable information after a flood, when other clearing works are enjoying priority.

Contrary to the approaches put forward by Parker and Neal (1990), Smith and Handmer (1986) and Krzysztofowicz and Davis (1983) discussed a methodology for evaluating an FFWRS which could be used at micro-level. This methodology is built on two elements, namely a model of an FFWRS and a performance evaluation. The former encompasses a mathematical description of the physical aspects that occur during floods, while the latter renders a measurement of the behaviour of an FFWRS. Jointly the two aspects mentioned constitute an evaluation model. Simplified criteria were proposed by Smith and Handmer (1986) to evaluate the efficiency and effectiveness of an integrated FFWRS.

\section{Stage development model}

Parker and Fordham (1996) applied a specific methodology in the European Union, with specific attention to the Netherlands, the United Kingdom including Scotland, Northern Ireland, England and Wales, Germany, France and Portugal. This methodology entails a staged development model that has been developed to simplify an FFWRS over time. The model consists of five stages of development and depicts a prescriptive approach to FFWRS. In addition to the five development stages, 14 criteria are established for evaluating an FFWRS and these differ from the evaluation procedures proposed by Krzysztofowicz and Davis (1983) and
Smith and Handmer (1986). The level of development of an FFWRS is measured in terms of a five-point scale ranging from one (undeveloped) to five (advanced). The staged development model can be represented in table form and will now be discussed briefly (Table 1).

In order to use the above-mentioned prescriptive approach, a country has to formulate a clear philosophy regarding FFWRS. Should the philosophy be absent, the level of development will receive a value of 1 under Criterion 1, while countries with a strong philosophy will receive a point of 4 or 5 . Countries with underdevelopment will have virtually no FFWRS in use and will cover less than $10 \%$ of a geographical area. In contrast to these, countries with a higher level of development (three and higher) have more than $50 \%$ of the geographical area covered by an FFWRS. An improvement in FFWRS can be attained by investing in broadcasting and response systems of flood forecasting and warning methods. Where the FFWRS is poorly developed, low technology will be present and little if any attempt will be in evidence to improve warning-broadcasting methods. The legal support of an FFWRS (Criterion 5) may possibly not exist at all, or be very poor, with the result that flood warning does not necessarily exist (Criterion 6), and a crude manner of broadcasting (Criterion 7) is therefore present. A fully fledged FFWRS is based on knowledge of an effective system (Criterion 10) that is deduced from the performance (Criterion 12) of an FFWRS, Criterion 11 is used to improve an FFWRS by means of post-flood incidents and also to disclose lessons learned from the public. A well-developed and mature FFWRS is also founded on national standards and on a positive cooperative culture (Criterion 13) with interactive agreements and commitments (Criterion 14).

\section{Flood forecasting, warning and response systems for South Africa}

As far as the FFWRS in South Africa is concerned, there is very little, if any, formal flood warning available. A flood warning communication system based on daily rainfall data and antecedent precipitation indices was developed by Alexander in 1993 and installed by the Department of Water Affairs and Forestry (DWAF) in June 1993. This system is depicted in diagram form in Fig. 3; for more particulars Alexander (1993) can be consulted. Owing to various reasons this system has since fallen into disuse.

DWAF is operating and improving a relatively advanced FFWRS in the Vaal and Orange River systems. A flood office is opened in Pretoria during floods in these rivers to co-ordinate dam operations and information dissemination.

At local level, regularly flooded communities are keen to be part of flood warning systems. Examples are Alexandria on the Jukskei River and Ladysmith on the Klip River.

The SA Weather Service is primarily responsible for the forecasting of flood-producing rainfall. Three systems are used for this purpose, namely a mathematical weather model, geostationary satellite images and a radar observation station. Notwithstanding some erroneous warnings which had been issued in the past, the mathematical weather models have managed to forecast major flood incidents correctly. Alexander(1993) mentioned that various floods (Natal 1987) had been forecast by the then Weather Bureau five days ahead of occurrence. However, loss of life still occurred since there was no effective response to the aforementioned forecast. Radar equipment currently used is old and unsophisticated, and bad telephone communication between measuring stations and the SA Weather Service still features during floods (DWAF, 1993). The communication system (Fig. 3) is in itself not a flood warning 


\begin{tabular}{|c|c|c|c|}
\hline \multicolumn{4}{|c|}{$\begin{array}{c}\text { TABLE } 1 \\
\text { Staged development model of flood forecasting, warning and response systems }\end{array}$} \\
\hline \multirow[t]{2}{*}{ Criteria } & \multicolumn{3}{|c|}{ Development states } \\
\hline & 1 & 2 and 3 & 4 and 5 \\
\hline 1. Flood warning philosophy & Rudimentary & Intermediate & Advanced \\
\hline 2. Dominance of forecasting vs. warning & Forecast dominant & Equal & $\begin{array}{l}\text { Equal and improved } \\
\text { accuracy }\end{array}$ \\
\hline 3. Application of technology to FFWRS & Model with manual & Mixture & Fully automated \\
\hline 4. Geographical coverage & $<10 \%$ & $>10 \%<50 \%$ & $>50 \%$ \\
\hline 5. Laws relating to FFWRS & No laws/ permissive & Laws & Laws with liability \\
\hline 6. Content of warning messages to public & 'Blanket': general location & $\begin{array}{c}\text { Mixed: } \\
\text { Location/timing }\end{array}$ & $\begin{array}{c}\text { 'Target': } \\
\text { severity/location \& timing }\end{array}$ \\
\hline 7. Methods of disseminating flood warning & General broadcast & Wardens/agencies/police & $\begin{array}{l}\text { Personal phone/fax/ } \\
\text { pager' }\end{array}$ \\
\hline $\begin{array}{l}\text { 8. Attitudes to freedom of risk/hazard } \\
\text { information }\end{array}$ & Little, request only & $\begin{array}{l}\text { Restricted to general } \\
\text { flood plain }\end{array}$ & Open specific property \\
\hline 9. Public education about warnings & Minimum & Some, e.g. colour codes & Fully informed \\
\hline 10. Knowledge of FFWRS effectiveness & Denial of failure & Recognise limitations & Research tested \\
\hline 11. Dissemination of lessons learned & Little & Partial & Full \\
\hline 12. Performance targets and monitoring & None & Key indicators & $\begin{array}{l}\text { Accuracy/timely/ } \\
\text { reliability }\end{array}$ \\
\hline 13. National standards & Parochial & $\begin{array}{l}\text { National/regional } \\
\text { variations }\end{array}$ & $\begin{array}{l}\text { National/ } \\
\text { International }\end{array}$ \\
\hline 14. Organisational culture & Independent & Agency liaison & $\begin{array}{l}\text { Service level agreement } \\
\text { with agencies }\end{array}$ \\
\hline \multicolumn{4}{|l|}{ Source: Parker and Fordham (1996) } \\
\hline $\begin{array}{l}\text { Explanations of development stages: } \\
\text { 1: Basic - little development } \\
\text { 2-3: Improved performance, but some failures } \\
\text { 4-5: More advanced performance; failures red }\end{array}$ & $\begin{array}{l}\text { apparent } \\
\text { ced }\end{array}$ & & \\
\hline
\end{tabular}

system. Effective flood warning cannot be issued by national authorities since additional information is required for this purpose. Warning must be issued at local government level (Alexander, 1993). DWAF does indeed issue warnings to the public via the media and notifies specific civil defence units if it is in possession of relevant information. Existing disaster management services still have an important role to play with regard to flood warning and disasters (DWAF in June 1993).

For the purposes of a new flood management policy a new communication system should be developed for South Africa. While the MARNET communication system functioned well in the past, this system now has limited application possibilities. The reasons for this are limited funds (DWAF, 1998), and the fact that the system is being moved to the Department of Provincial and
Local Government, which at present does not have the expertise to maintain the MARNET System. The private sector can be used fruitfully in this regard. The latest development in cellular phones could be applied as an excellent communication system. When adequate satellites have been launched, virtually the whole surface of the earth will be covered by a communications blanket. Cellular phone operators are available $24 \mathrm{~h}$ a day and are already engaged in providing aid in emergency situations.

Secondly, a formal national flood forecasting, warning and response centre must be established for South Africa. This centre must be able to receive, process and issue data in an intelligible way. The present Disaster Management Centre can also be used for this purpose.

Thirdly, the new disaster management policy for South Africa needs to make provision for the installation of an appropriate 


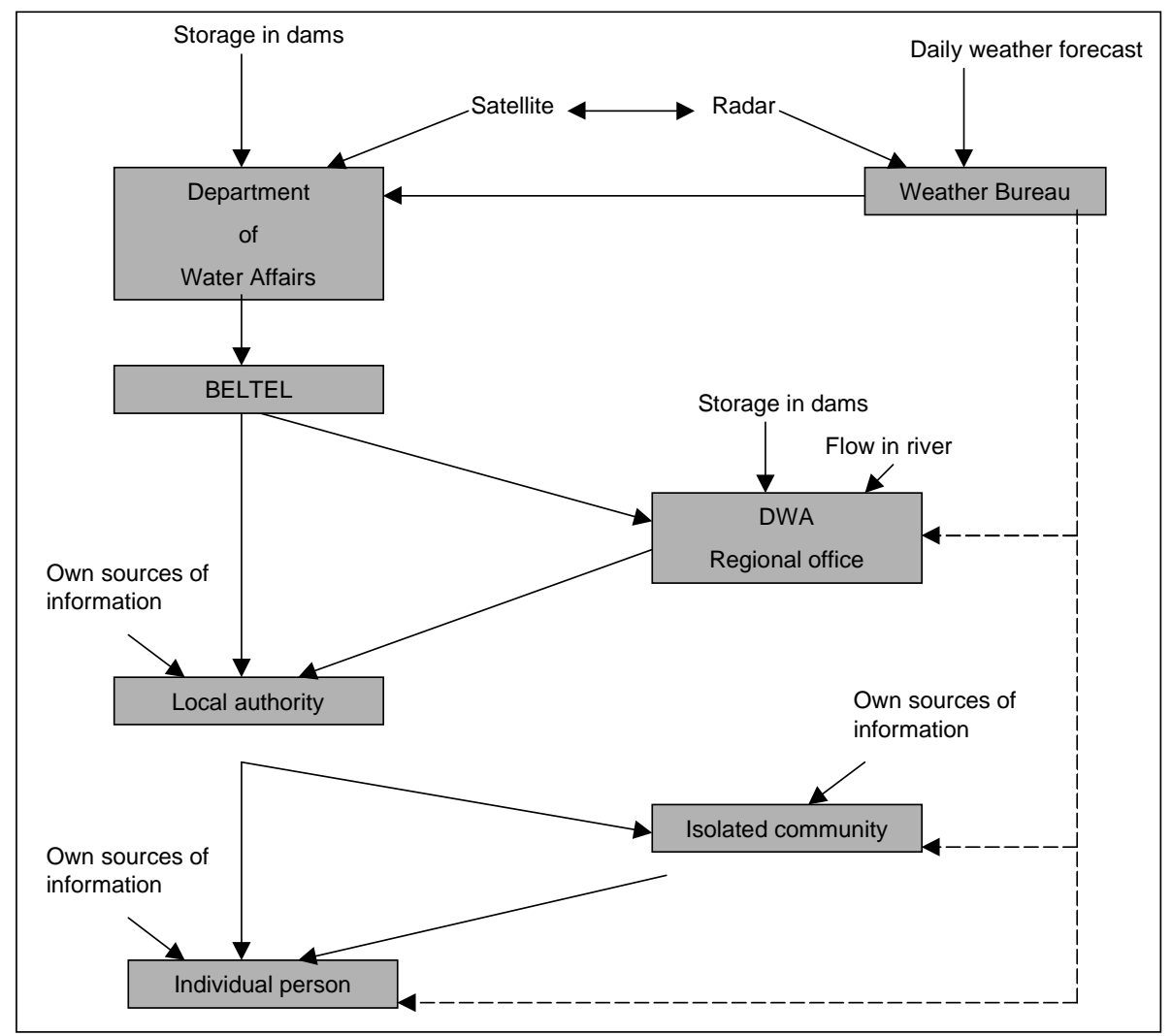

Figure 3

Flood warning communication system

Source: Alexander (1986)

national flood forecasting, warning and response system (FFWRS). Provincial and local authorities must be empowered in terms of this policy to install their own FFWRS, which can be adapted to their own unique circumstances. In order therefore to reduce the social disruption and damage of floods, local authorities must promote flood awareness in communities by providing flood data and advice to owners, flood plain inhabitants, visitors, potential purchasers of land and investors. Research has shown that a high degree of carelessness is evident in the public concerning flood hazards. DWAF in June 1993 referred to this as follows: "A lack of specialist advice to smaller communities on how to deal with flood situations". Appropriate flood and disaster awareness programmes should therefore be compiled for communities at local level.

Disaster education normally includes the identification of leaders in communities. In this way the ability of the community to issue warnings and to respond effectively to them can be improved. Warning systems for a nation such as South Africa will differ considerably in relation to the value system of regions. The issuing of warnings for the informal sector will differ substantially from warnings in the metropolitan area.

Last, but not the least, appropriate institutions to be tasked with the implementation of an FFWRS in South Africa have to be identified. A well-developed FFWRS, which is not implemented, is of no value. An appropriate FFWRS must be instituted in floodprone areas, irrespective of the type or degree of sophistication thereof. Even the best-designed system can fail in the absence of effective organisation, structure and sound leadership. Leadership is the driving force behind the implementation of a system. It includes co-ordination of tasks and activities and communication at all levels. A poorer system effectively implemented will function better than a better system poorly implemented. The first step in ensuring that a national FFWRS can be developed is to ensure that the required institutions in South Africa are in place. It is here that the new disaster management policy can fulfil an important role. National, provincial and local authorities should be empowered through appropriate acts, ordinances and regulations to ensure flood-plain sovereignty in South Africa. New and innovative thinking will have to be employed in the education of communities. Not only will new technology have to be used, but also new training and education methods will have to be developed. To this end suitable research will have to be undertaken.

\section{Conclusions and recommendations}

An FFWRS forms part of a total holistic approach to manage catchments sustainable, and if one component fails, the whole system is rendered dysfunctional. If the principles and functions of an FFWRS are not understood flood warning systems may be misused at very high costs in communities, which contributes to ineffective mitigation and prevention of potential flood losses. It can be concluded that an appropriate FFWRS contributes to sustainable integrated catch management in the sense that it mitigates potential flood losses. An FFWRS is distinguished as a costeffective option of flood reduction. Various elements are involved in an effective FFWRS, namely weather forecast, flood detection, flood warning, emergency organisations, users of warnings, response to warning, hazard delimitation, planning organisations, users of hazard prevention and responses to predictions.

In order to evaluate the effectiveness of an FFWRS, a staged development model is recommended. The staged development model consists of five stages of development and depicts a prescriptive approach to FFWRS. In addition to the five development stages, 14 criteria are established for evaluating an FFWRS, which vary from the flood warning philosophy to organisational culture. 
South Africa is currently still experiencing serious institutional problems. Because roles and responsibilities are not clearly identified for institutions involved in integrated catchment management, flood prevention and mitigation actions are ineffective. Institutional problems are arguably the biggest reason for the nonexistence of a formal FFWRS for South Africa at national as well as at regional level. The new Disaster Management Act is still not promulgated and further contributes to the unidentified roles and responsibilities of institutions involved in disaster management.

It is recommended that after the new Disaster Management Act has been promulgated an appropriate national flood management strategy needs to be formulated for South Africa. Institutions involved in disaster management need to be identified, and responsibilities thereof also need to be formulated. More specifically the following aspects need urgent attention to implement appropriate flood mitigation and prevention strategies for South Africa:

- Development of a new communication system.

- Establishment of a formal FFWR centre.

- Appropriate institutions to be tasked with the implementation of an FFWRS in South Africa have to be identified. A welldeveloped FFWRS, which is not implemented, is of no value. An appropriate FFWRS must be instituted in flood-prone areas, irrespective of the type or degree of sophistication thereof. The first step in ensuring that a national FFWRS can be developed is to ensure that the required institutions in South Africa are in place. A new national flood management strategy needs to be formulated for South Africa, which will execute the new Disaster Management Act, as far as floods are concerned.

- Leadership is the driving force behind the implementation of a system. To ensure the effective implementation of an FFWRS and the use of the technology, new training and education methods must be developed. People need to be trained in disaster management issues and to understand the principles of holistic management. Education of communities is important and normally includes the identification of community leaders. Flood warning for metropolitan areas and the informal sector will therefore differ significantly.

\section{Acknowledgements}

The financial support by the Water Research Commission (WRC) is hereby acknowledged.

\section{References}

ADAMS WM (1995) Wetlands and floodplain development in dryland Africa. People Environ. Africa 13-21.

ALEXANDER WJR (1993) Flood Risk Reduction Measures. Dept. of Civil Eng., Univ. of Pretoria, Pretoria.

BANCID (BANGLADESH NATIONAL COMMITTEE OF THE INTERNATIONAL COMMISSION ON IRRIGATION AND DRAINAGE) (1995) Non-structural Aspects of Flood Management in Bangladesh. Dhaka: BANCID.

DEMPSTER JIM and BRAMMER H(1995) Flood action plan-Bangladesh. WARBA 31 301-305.

DEPARTMENT OF WATER AFFAIRS AND FORESTRY (DWAF) (1998) Green Paper on a National Water Policy for South Africa. Pretoria: Department of Water Affairs and Forestry.

DEPARTMENT OF WATER AFFAIRS AND FORESTRY (DWAF) (1993) Revision of the Flood Management Policy. Supporting documentation for Task 2, formulated as the determination and evaluation of the nature of flood impacts and the interpretation of the lessons learnt for application in a flood management policy. Pretoria: Directorate: Strategic planning.

DOWNING TE (1977) Warning for Flash Floods in Boulder, Colorado. Urban Drainage and Flood Control District Denver, Colorado. Working Paper 31. Institute of Behavioural Science. University of Colorado.

DU PLESSIS LA (1998) Flood Damage Simulation for Irrigation Farmers in the Lower Orange and Umfolozi River as Part of a Sustainable and Integrated Flood Plain Management System. Unpublished Ph.D. Thesis, Univ. of the Free State, Bloemfontein.

GALLOWAY GE (1995) New directions in floodplain management. WARBA 31(3) 351-357.

GHOSH A (1991) Eighth Plan: Challenges and possibilities -X. Economic Political Weekly 26 (14) 865-874.

HAQUE CE and ZAMAN MQ (1993) Human responses to riverine hazards in Bangladesh: A proposal for sustainable floodplain development. World Development 21(1) 93-107.

KRZYSZTOFOWICZ R and DAVIS DR (1983) A methodology for evaluation of flood forecast-response systems (1. Analysis and Concepts). Water Resour. Res. 19 (6) 1423-1429.

NEW SOUTH WALES GOVERNMENT (1986) Floodplain Development Manual. Unpublished Report, New South Wales Dept. of Water Resources, Canberra.

PARKER DJ and FORDHAM M (1996) An evaluation of flood forecasting, warning and response systems in the European Union. Water Res. Manage. 10 279-302.

PARKER DJ and NEAL J (1990) Evaluating the Performance of Flood Warning Systems. 137-156.

PARKER DJ (1995) Floodplain development policy in England and Wales. Appl. Geogr. 15 (4) 341-363.

SMITH DI and HANDMER JW (1986) Flood Warning in Australia. Centre for Resource and Environmental Studies, Canberra. 
